\title{
Magnetic Reluctance Method for Dynamical Modeling of Squirrel Cage Induction Machines
}

\author{
Jalal Nazarzadeh and Vahid Naeini \\ Faculty of Engineering \\ Shahed University, Tehran
}

Iran

\section{Introduction}

Nowadays, induction machines play important role in electromechanical energy conversion in industry. These machines are often operated in critical conditions where can cause unexpected failures and outages. Generally, stator and bearing faults, broken rotor bar and end-rings, air-gap irregularities are some of the major faults in an induction machine (Al-Shahrani, 2005; Sprooten, 2007) which may be situated the induction machines in out of service (Siddique et al., 2005). Fourier analysis for stator currents (Bellini et al., 2001; Benbouzid, 2000; Jung et al., 2006), torque and rotor speed, acoustic noise and temperature analysis (Siddique et al., 2005) are some classical techniques which introduced for identification and diagnosis of induction machines faults. Additionally, other heuristic methods were proposed to monitor of the induction machines for fault detection. For instance, neural network modelling were applied to monitor an induction machine for fault detection (Su \& Chong, 2007). Also, space vector of rotor magnetic field (Mirafzal \& Demerdash, 2004) based on artificial intelligent approaches and pendulous oscillation of the rotor magnetic field were proposed. Recently, a new technique based on the analysis of three-phase stator current envelopes was presented (Mirafzalet \& Demerdash, 2008). In all monitoring and fault detection techniques, we need to tune up the monitoring systems based on response of induction machines for proper operations. However, experimental set up for testing any arbitrary fault conditions are not practical. Thus, an accuracy dynamic and steady state models of induction machines are very important for this propose.

Also, for dynamical modelling of induction machines, space harmonic distribution, core saturation and loss are often neglected in abc quantitative and two-axis methods (Krause et al., 1995). Thus, these approaches do not have an efficient accuracy for modelling of induction machines in asymmetrical and non-linear conditions. For considering distribution rotor bars, coupled magnetic circuit method (Muñoz \& Lipo, 1999), abc quantitative based on rotor bar currents (Alemi \& Nazarzadeh, 1996) can be utilized. Furthermore, winding function method may be used to include the stator winding distribution effect in the air gap flux (Luos et al., 1995). However, in all mentioned methods, the core saturation, stator and rotor teeth effects and distributions of the rotor and stator windings can not be investigated, simultaneously. Also, Finite Element Method (FEM) is a professional technique for analysis of any electromagnetic systems, which needs to magnetic and geometry details of the systems (Faiz 
et al., 2002). This method is very accurate and flexible, but due to complexity, the dynamical modelling of an induction machine is quite complicated. Contrary to FEM, the Magnetic Equivalent Circuit Method (MECM) can apply to analysis of the electro magnetics problems with lower complexity. Magnetic saturation, space harmonics in stator and rotor teeth, stator windings and distributed structure of a squirrel-cage rotor can be considered by MECM for modelling and analysis of any induction machines (Jeong et al., 2003; Ostovic, 1989). In this approach, the non-linear reluctances of flux paths use to configure magnetic equivalent circuit. This method has less complexity than FEM for dynamical modelling of induction machines. Therefore, developing an exact details model of induction machine for analysis of transient, sensitivity and fault diagnosis in the asymmetrical conditions are very essential.

The present chapter introduces methodology of MECM for modelling and analysis of asymmetrical non-linear systems in transient and steady state conditions. MECM is very suitable method for finding a generalized accurate dynamical model of squirrel cage induction machines with asymmetrical conditions. For evaluation of the method, several simulations in linear and non-linear conditions are made. Also, some simulations results for induction machines with broken bar faults and core saturation conditions are included to illustrate capability of the method in asymmetrical conditions.

\section{Electric and magnetic based model of squirrel cage induction machines}

For detailed modelling of any electromagnetic systems, we have to find a correlation between electric and magnetic variables of the system. Generally, a set of non-linear differential equations presents dynamical model of a electromagnetic system that by using numerical analysis, transient response of the electrical variables can be obtained. In addition, non-linear algebraic equations illustrate non-linear relations between electrical and magnetic variables. MECM provides an augmented model of the electromagnetic systems, in which we can achieve all variables of the systems in transient and steady state, simultaneously. Also, the main advantages of MECM for modelling of induction machines are; simple algorithm for including distribution winding, stator and rotor teeth effects and magnetic core saturation phenomena. Global non-linear model of squirrel cage induction machines can be offered in algebraical (magnetic) and differential (electric) equations which will be presented in the following sections.

\section{Magnetic equivalent circuit of induction machines}

Fig. 1 shows a part of rotor and stator structures for a typical squirrel cage induction machine that magnetic circuit elements are presented for rotor and stator teeth and yoke. Numbers of rotor and stator teeth are considered by $h$ and $l$, respectively. Also in this figure, magnetic mutual permeances of rotor and stator teeth in air gap are shown. Due to non-linear characteristics of flux and magnetic current in iron core, permeances of the rotor and stator in the magnetic cores are illustrated as non-linear elements. $G_{i, j}$ is linear permeance of flux path between $i^{\text {th }}$ stator and $j^{\text {th }}$ rotor teeth in the air gap.

\subsection{Magnetic node equations}

Due to the fact that magnetic permeances of each stator and rotor teeth make several magnetic loops in the air gap, we apply node magnetic potential equations to the each air gap nodes for 


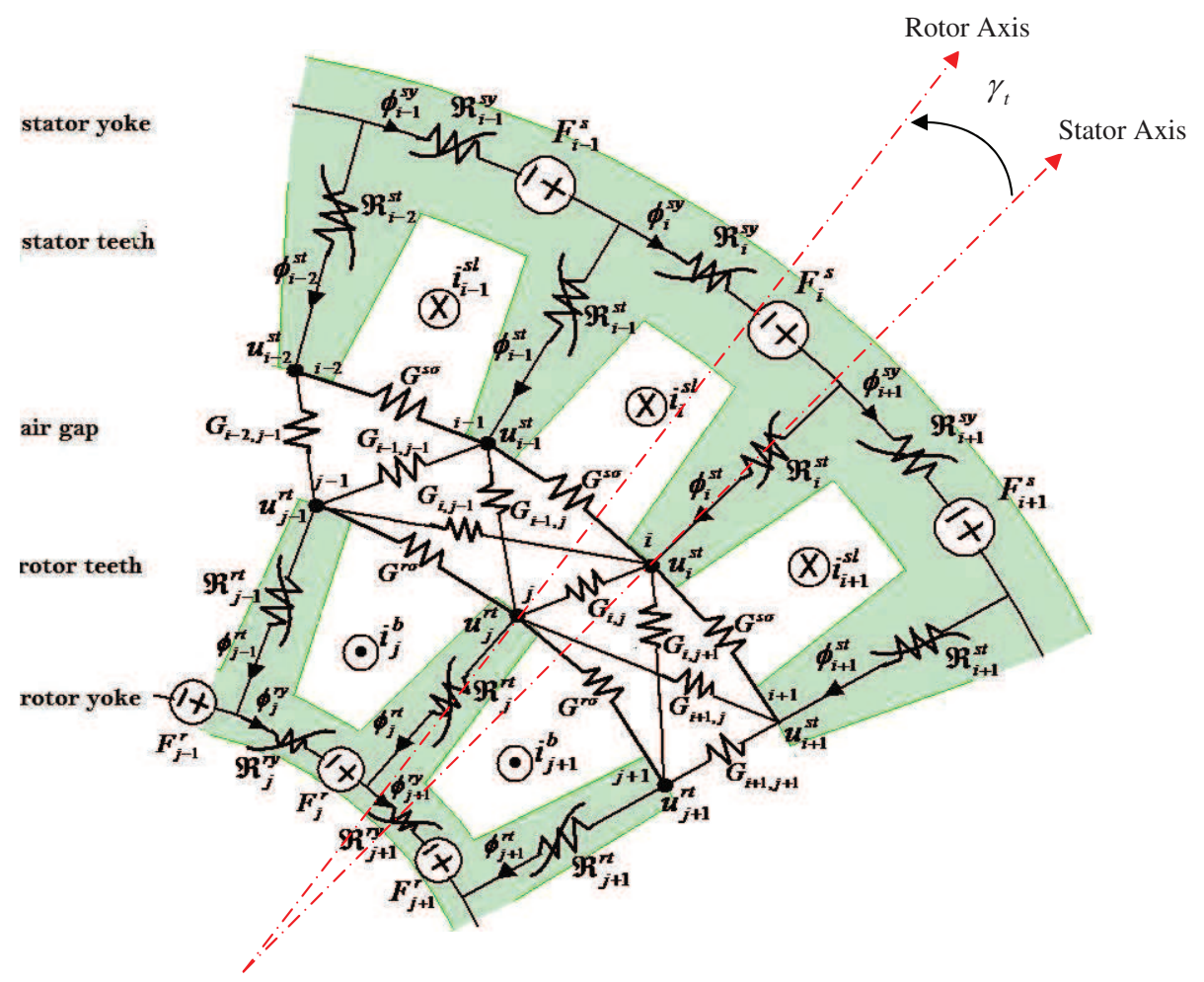

Fig. 1. Magnetic equivalent circuit of induction machine

simplicity in algebraic magnetic equations. For instance, sum of magnetic fluxes in $i^{\text {th }}$ air gap node (stator tooth) have to be zero; thus we can write:

$$
\left(u_{i}^{s}-u_{i+1}^{s}\right) G^{s \sigma}+\left(u_{i}^{s}-u_{i-1}^{s}\right) G^{s \sigma}+\left(u_{i}^{s}-u_{1}^{r}\right) G_{i 1}+\cdots+\left(u_{i}^{s}-u_{l}^{r}\right) G_{i l}=\phi_{i}^{s t}
$$

where $u_{i}^{s}, u_{i}^{r}$ and $\phi_{i}^{s t}$ are magnetic potential of stator, rotor and flux of $i^{\text {th }}$ stator tooth and $G^{s \sigma}$ and $G_{i, j}$ are permeances of stator neighbour slots and mutual permance between $i^{\text {th }}$ stator with $j^{\text {th }}$ rotor teeth, respectively.

Similar Eq. (1), continuity principle in the teeth fluxes at $i^{\text {th }}$ rotor node yields as:

$$
\left(u_{i}^{r}-u_{i+1}^{r}\right) G^{r \sigma}+\left(u_{i}^{r}-u_{i-1}^{r}\right) G^{r \sigma}+\left(u_{i}^{r}-u_{1}^{s}\right) G_{i 1}+\cdots+\left(u_{i}^{r}-u_{h}^{s}\right) G_{i h}=-\phi_{i}^{r t}
$$

In Eq. (2), $\phi_{i}^{s t}$ and $G^{r \sigma}$ are flux of $i^{\text {th }}$ rotor tooth and permeance of rotor slot, respectively. Consequently, node potential equations for equivalent circuit of Fig. 1 along the air gap can be written as:

$$
\begin{gathered}
\mathbf{A}_{s s} \mathbf{U}_{s t}+\mathbf{A}_{s r} \mathbf{U}_{r t}=\Psi_{s t} \\
\mathbf{A}_{r s} \mathbf{U}_{s s}+\mathbf{A}_{r r} \mathbf{U}_{r t}=-\Psi_{r t}
\end{gathered}
$$


where $\mathbf{A}_{s s} \in \mathbb{R}^{h \times h} \hat{\mathbf{a}} \breve{A}$ ć, $\mathbf{A}_{r r} \in \mathbb{R}^{l \times l}$ and $\mathbf{A}_{s r} \in \mathbb{R}^{h \times l}$ are air gap permeance coefficients matrices that we can written as:

$$
\begin{aligned}
& \mathbf{A}_{s s}=\left[\begin{array}{ccccccc}
2 G^{s \sigma}+\sum_{j=1}^{l} G_{1, j} & -G^{s \sigma} & 0 & \cdots & 0 & 0 & -G^{s \sigma} \\
-G^{s \sigma} & 2 G^{s \sigma}+\sum_{j=1}^{l} G_{2, j} & -G^{s \sigma} & \cdots & 0 & 0 & 0 \\
\vdots & \vdots & \vdots & \ddots & \vdots & \vdots & \vdots \\
-G^{s \sigma} & 0 & 0 & \cdots & 0 & -G^{s \sigma} & 2 G^{s \sigma}+\sum_{j=1}^{l} G_{h, j}
\end{array}\right] \\
& \mathbf{A}_{r r}=\left[\begin{array}{ccccccc}
2 G^{r \sigma}+\sum_{i=1}^{h} G_{i, 1} & -G^{r \sigma} & 0 & \cdots & 0 & 0 & -G^{r \sigma} \\
-G^{r \sigma} & 2 G^{r \sigma}+\sum_{i=1}^{h} G_{i, 2} & -G^{r \sigma} & \cdots & 0 & 0 & 0 \\
\vdots & \vdots & \vdots & \ddots & \vdots & \vdots & \vdots \\
-G^{r \sigma} & 0 & 0 & \cdots & 0 & -G^{r \sigma} & 2 G^{r \sigma}+\sum_{i=1}^{h} G_{i, l}
\end{array}\right] \\
& \mathbf{A}_{s r}=\mathbf{A}_{r s}^{T}=\left[\begin{array}{cccc}
G_{1,1} & G_{1,2} & \cdots & G_{1, l} \\
G_{2,1} & G_{2,2} & \cdots & G_{2, l} \\
\vdots & \vdots & \ddots & \vdots \\
G_{h, 1} & G_{h, 2} & \cdots & G_{h, l}
\end{array}\right]
\end{aligned}
$$

Also, $\Psi_{s t} \in \mathbb{R}^{h \times 1}, \Psi_{r t} \in \mathbb{R}^{l \times 1}, \mathbf{U}_{s t} \in \mathbb{R}^{h \times 1}$ and $\mathbf{U}_{r t} \in \mathbb{R}^{l \times 1}$ are stator and rotor teeth fluxes vectors, stator and rotor magnetic scalar potentials vectors, respectively. These vectors can be presented as:

$$
\begin{aligned}
\Psi_{s t} & =\left[\begin{array}{llll}
\phi_{1}^{s t} & \phi_{2}^{s t} & \cdots & \phi_{h}^{s t}
\end{array}\right]^{T} \\
\Psi_{r t} & =\left[\begin{array}{llll}
\phi_{1}^{r t} & \phi_{2}^{r t} & \cdots & \phi_{l}^{r t}
\end{array}\right]^{T} \\
\mathbf{U}_{s t} & =\left[\begin{array}{llll}
u_{1}^{s t} & u_{2}^{s t} & \cdots & u_{h}^{s t}
\end{array}\right]^{T} \\
\mathbf{U}_{r t} & =\left[\begin{array}{llll}
u_{1}^{r t} & u_{2}^{r t} & \cdots & u_{l}^{r t}
\end{array}\right]^{T}
\end{aligned}
$$

In Eq. (5), $G^{s \sigma}$ is linear permeances between each successive stator slots with constant geometric permeability. This permeance can be obtained from (see Fig. 1):

$$
G^{s \sigma}=\mu_{0} \frac{A^{s \sigma}}{L^{s \sigma}}
$$

Similarly, for $G^{r \sigma}$ we can write:

$$
G^{r \sigma}=\mu_{0} \frac{A^{r \sigma}}{L^{r \sigma}}
$$

where $A^{s \sigma}, L^{s \sigma}, A^{r \sigma}, L^{r \sigma}$ and $\mu_{0}$ are cross section and length of stator and rotor slot opening and air permeability, respectively. Furthermore, mutual permeance between $i^{\text {th }}$ and $j^{\text {th }}$ slots of the rotor and stator teeth depends to rotor mechanical angle $\left(\gamma_{i}(t)\right)$, momentarily. Fig.2-a 


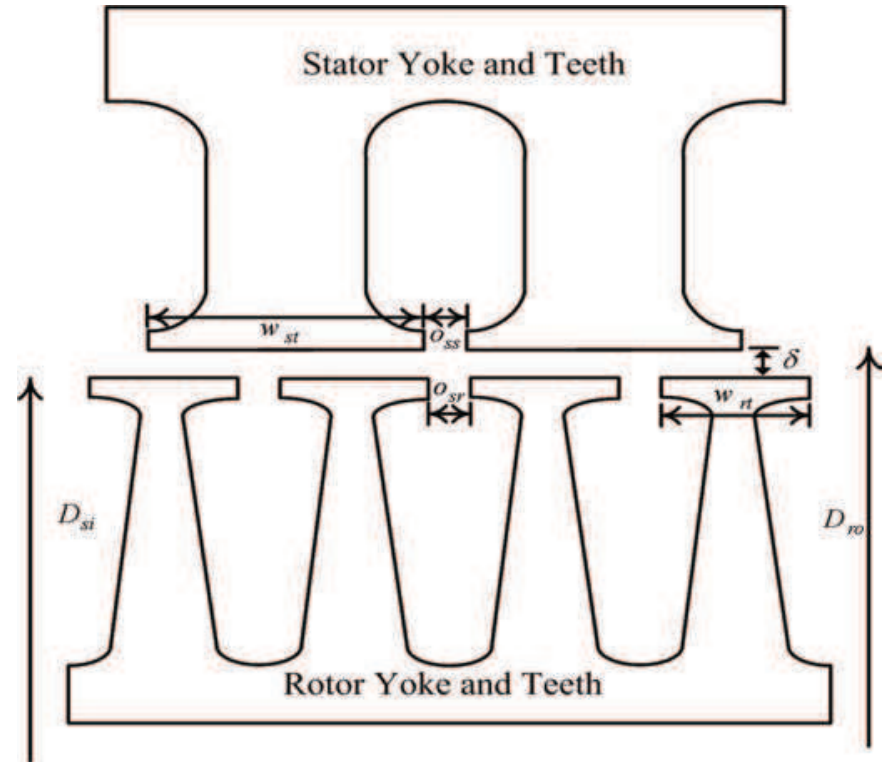

(a) Geometric of the stator and rotor teeth

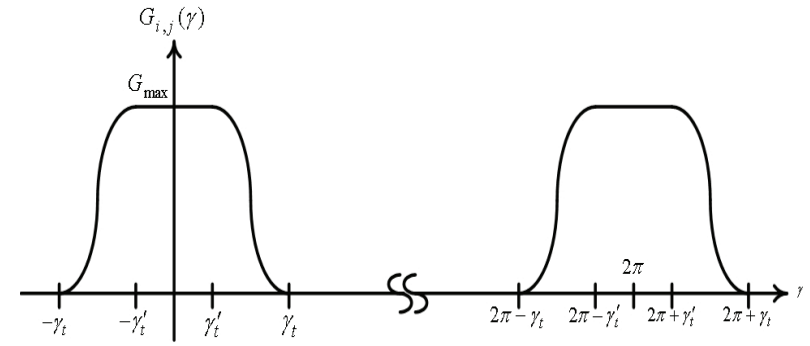

(b) Approximation function

Fig. 2. A typical air gap permeance between stator and rotor teeth

shows a typical geometry of the stator and rotor teeth. In this case, stator and rotor mutual permeance can be approximated by:

$$
G_{i, j}(\gamma)=\left\{\begin{array}{lc}
G_{\max } & 0<\gamma<\gamma_{t}^{\prime} \quad 2 \pi-\gamma_{t}^{\prime}<\gamma<2 \pi \\
G_{\max } \frac{1+\cos \pi \frac{\gamma-\gamma_{t}^{\prime}}{\gamma_{t}-\gamma_{t}^{\prime}}}{2} & \gamma_{t}^{\prime}<\gamma<\gamma_{t} \\
G_{\max } \frac{1+\cos \pi \frac{\gamma-2 \pi+\gamma_{t}^{\prime}}{\gamma_{t}-\gamma_{t}^{\prime}}}{2} & 2 \pi-\gamma_{t}<\gamma<2 \pi-\gamma^{\prime} \\
0 & \gamma_{t}<\gamma<2 \pi-\gamma_{t}
\end{array}\right.
$$

where $\gamma_{t}$ and $\gamma_{t}^{\prime}$ are two mechanical angles which are depended to the stator and rotor teeth geometry. For instance, in Fig. 2-a; $\gamma_{t}$ and $\gamma^{\prime} t$ can be obtained as: 


$$
\begin{gathered}
\gamma_{t}=\frac{w_{s t}+w_{r t}+o_{s s}+o_{s r}}{D_{a g}} \\
\gamma_{t}^{\prime}=\frac{\left|w_{s t}-w_{r t}\right|}{D_{a g}}
\end{gathered}
$$

where $w_{s t}, w_{r t}, o_{s s}$ and $o_{s r}$ are dimensions of stator and rotor which are shown in Fig. 2-a and $D_{a g}$ is :

$$
D_{a g}=\frac{D_{s i}+D_{r o}}{2}
$$

The maximum value of air gap permeance $G_{\max }$ can be written as

$$
G_{\max }=\mu_{0} \frac{l \times \min \left[w_{s t}, w_{r t}\right]}{\delta}
$$

where $l$ and $\delta$ are lengths of machine and air gap.

\subsection{Magnetic mesh equations}

Eqs. (3) and (4) present $l+h$ node equations which are shown relation between magnetic potentials of teeth nodes with stator and rotor teeth fluxes. Attention to Fig. 1, two neighbour stator teeth and yoke paths make a simple mesh in each stator slots, that sum of the magnetic potentials in these mesh have to be zero. For instance, magnetic mesh equation in $i^{\text {th }}$ and $(i+1)^{\text {th }}$ stator teeth and yoke can be written as:

$$
u_{i}^{s t}-u_{i-1}^{s t}-\Re_{i-1}^{s t} \phi_{i-1}^{s t}+\Re_{i}^{s t} \phi_{i}^{s t}+\Re_{i}^{s y} \phi_{i}^{s y}=F_{i}^{S}
$$

Similarly, mesh equation for $i^{\text {th }}$ rotor tooth and yoke with $(i+1)^{\text {th }}$ rotor tooth can be obtained as:

$$
u_{i}^{r t}-u_{i-1}^{r t}+\Re_{i-1}^{r t} \phi_{i-1}^{r t}-\Re_{i}^{r t} \phi_{i}^{r t}+\Re_{i}^{r y} \phi_{i}^{r y}=F_{i}^{r}
$$

Thus, magnetic mesh equations for all rotor and stator meshes can be expressed as:

$$
\begin{aligned}
& \mathbf{A}_{u s t} \mathbf{U}_{s t}+\mathbf{A}_{\Psi_{s y}} \Psi_{s y}+\mathbf{A}_{\varphi s t} \Psi_{s t}=\mathbf{F}_{s} \\
& \mathbf{A}_{u r t} \mathbf{U}_{r t}+\mathbf{A}_{\phi r y} \Psi_{r y}+\mathbf{A}_{\phi r t} \Psi_{r t}=\mathbf{F}_{r}
\end{aligned}
$$

In Eqs. (21) and (22), $\mathbf{A}_{\phi s t} \in \mathbb{R}^{h \times h}$ and $\mathbf{A}_{\phi r t} \in \mathbb{R}^{l \times l}$ are diagonal coefficients matrices of the stator and rotor teeth reluctance that we can find as:

$$
\mathbf{A}_{\phi s t}=\left[\begin{array}{cccccc}
\Re\left(B_{1}^{s t}\right) & 0 & 0 & \cdots & 0 & -\Re\left(B_{h}^{s t}\right) \\
-\Re\left(B_{1}^{s t}\right) & \Re\left(B_{2}^{s t}\right) & 0 & \cdots & 0 & 0 \\
0 & -\Re\left(B_{2}^{s t}\right) & \Re\left(B_{3}^{s t}\right) & \cdots & 0 & 0 \\
\vdots & \vdots & \vdots & \ddots & \vdots & \vdots \\
0 & \cdots & 0 & \cdots & \Re\left(B_{h-1}^{s t}\right) & 0 \\
0 & \cdots & 0 & \cdots & -\Re\left(B_{h-1}^{s t}\right) & \Re\left(B_{h}^{s t}\right)
\end{array}\right]
$$




$$
\mathbf{A}_{\phi r t}=\left[\begin{array}{cccccc}
-\Re\left(B_{1}^{r t}\right) & 0 & 0 & \cdots & 0 & \Re\left(B_{l}^{r t}\right) \\
\Re\left(B_{1}^{r t}\right) & -\Re\left(B_{2}^{r t}\right) & 0 & \cdots & 0 & 0 \\
0 & \Re\left(B_{2}^{r t}\right) & -\Re\left(B_{3}^{r t}\right) & \cdots & 0 & 0 \\
\vdots & \vdots & \vdots & \ddots & \vdots & \vdots \\
0 & \cdots & 0 & \cdots & -\Re\left(B_{l-1}^{r t}\right) & 0 \\
0 & \cdots & 0 & \cdots & \Re\left(B_{l-1}^{r t}\right) & -\Re\left(B_{l}^{r t}\right)
\end{array}\right]
$$

also $\mathbf{A}_{\phi s y} \in \mathbb{R}^{h \times h}$ and $\mathbf{A}_{\phi r y} \in \mathbb{R}^{l \times l}$ are stator and rotor yoke reluctance coefficients matrices which can be written as

$$
\begin{aligned}
& \mathbf{A}_{\phi s y}=\operatorname{diag}\left(\Re\left(B_{1}^{s y}\right), \Re\left(B_{2}^{s y}\right), \cdots, \Re\left(B_{h}^{s y}\right)\right) \\
& \mathbf{A}_{\phi r y}=\operatorname{diag}\left(\Re\left(B_{1}^{r y}\right), \Re\left(B_{2}^{r y}\right), \cdots, \Re\left(B_{l}^{r y}\right)\right)
\end{aligned}
$$

which $\Psi_{s y} \in \mathbb{R}^{h \times 1}, \Psi_{r y} \in \mathbb{R}^{l \times 1}$ are stator and rotor yoke fluxes vectors and $\mathbf{F}_{S} \in \mathbb{R}^{h \times 1}$ and $\mathbf{F}_{r} \in \mathbb{R}^{l \times 1}$ are stator and rotor ampere-turn vectors, respectively. These vectors are considered as:

$$
\begin{aligned}
\Psi_{s y} & =\left[\begin{array}{llll}
\phi_{1}^{s y} & \phi_{2}^{s y} & \cdots & \phi_{h}^{s y}
\end{array}\right]^{T} \\
\Psi_{r y} & =\left[\begin{array}{llll}
\phi_{1}^{r y} & \phi_{2}^{r y} & \cdots & \phi_{l}^{r y}
\end{array}\right]^{T} \\
\mathbf{F}_{s} & =\left[\begin{array}{llll}
F_{1}^{s} & F_{2}^{s} & \cdots & F_{h}^{s}
\end{array}\right]^{T} \\
\mathbf{F}_{r} & =\left[\begin{array}{llll}
F_{1}^{r} & F_{2}^{r} & \cdots & F_{l}^{r}
\end{array}\right]^{T}
\end{aligned}
$$

Also, $\mathbf{A}_{u s t} \in \mathbb{R}^{h \times h}$ and $\mathbf{A}_{u r t} \in \mathbb{R}^{l \times l}$ are constant matrices which are given by:

$$
\mathbf{A}_{u s t}=\mathbf{A}_{u r t}=\left[\begin{array}{cccccc}
1 & 0 & 0 & \cdots & 0 & -1 \\
-1 & 1 & 0 & \cdots & 0 & 0 \\
0 & -1 & 1 & \cdots & 0 & 0 \\
\vdots & \vdots & \vdots & \ddots & \vdots & \vdots \\
0 & 0 & 0 & \cdots & 1 & 0 \\
0 & 0 & 0 & \cdots & -1 & 1
\end{array}\right]
$$

\subsection{Teeth and yoke flux relations}

For completing of the magnetic model of an induction machine, we need to find a relation between teeth and yoke fluxes in mesh equations (Eqs. (21) and (22)). Attention to Fig. 1, the relations between stator teeth and yoke fluxes can be obtained by applying magnetic flux continuity principle in the yoke nodes. Thus, we have:

$$
\phi_{i}^{s y}=\phi_{i}^{s t}+\phi_{i+1}^{s y}
$$


Similarly, relation between the rotor fluxes are:

$$
\phi_{j+1}^{r y}=\phi_{j}^{r t}+\phi_{j}^{r y}
$$

Eqs. (32) and (33) can be presented in matrix form as:

$$
\begin{aligned}
& \Psi_{s t}=\mathbf{A}_{s y t} \Psi_{s y} \\
& \Psi_{r t}=\mathbf{A}_{r y t} \Psi_{r y}
\end{aligned}
$$

where $\mathbf{A}_{s y t} \in \mathbb{R}^{h \times h}$ and $\mathbf{A}_{r y t} \in \mathbb{R}^{l \times l}$ can be written as

$$
\mathbf{A}_{r y t}=-\mathbf{A}_{s y t}=\left[\begin{array}{cccccc}
-1 & 1 & 0 & \cdots & 0 & 0 \\
0 & -1 & 1 & \cdots & 0 & 0 \\
0 & 0 & -1 & \cdots & 0 & 0 \\
\vdots & \vdots & \vdots & \ddots & \vdots & \vdots \\
0 & 0 & 0 & \cdots & -1 & 1 \\
1 & 0 & 0 & \cdots & 0 & -1
\end{array}\right]
$$

In a squirrel cage induction machine, a stator winding is not concentrated in single slot, but it is distributed along air gap for harmonics reduction, full utilization of core and reduction of mechanical stress to the winding. Thus, flux of stator coil equals the sum of fluxes of stator teeth in the coil pitch. If three phase flux vector of the stator windings denotes as $\Psi_{3 \phi}$, we can find a matrix relation between stator teeth and windings fluxes as:

$$
\Psi_{3 \phi}=\mathbf{M}_{c f} \Psi_{s t}
$$

where $\mathbf{M}_{c f} \in \mathbb{R}^{3 \times h}$ is a connected matrix which can be obtained based on the connection diagram of stator windings.

\section{Core saturation characteristic}

Generally, magnetic cores of any electrical machines have non-linear characteristic curve $(B-H)$, thus the elements of reluctance matrices in Eqs. (23) and (24) are depended to their fluxes. For inserting the non-linearity characteristic of the magnetic core to mesh equations, a non-linear permeability dependent to the core field density are used. For this purpose, a non-linear permeability is defined as:

$$
\mu(B)=\mu_{0} \mu_{r}(B)=\frac{\partial B}{\partial H}
$$

So, the reluctances of flux path in the stator and rotor cores can be written as:

$$
\Re\left(B_{i}^{k}\right)=\frac{L_{i}^{k}}{\mu\left(B_{i}^{k}\right) A_{i}^{k}} \quad \begin{gathered}
k=s y, s t, r y, r t \\
i=1,2, \ldots
\end{gathered}
$$

where $L_{i}^{k}$ and $A_{i}^{k}$ are $i^{t h}$ length and cross section of flux path in the stator and rotor cores, respectively. Tangent, exponential and piecewise linear functions may be used to approximate the saturation curve (Chen et al., 2005). In this chapter, the magnetic core permeability is 


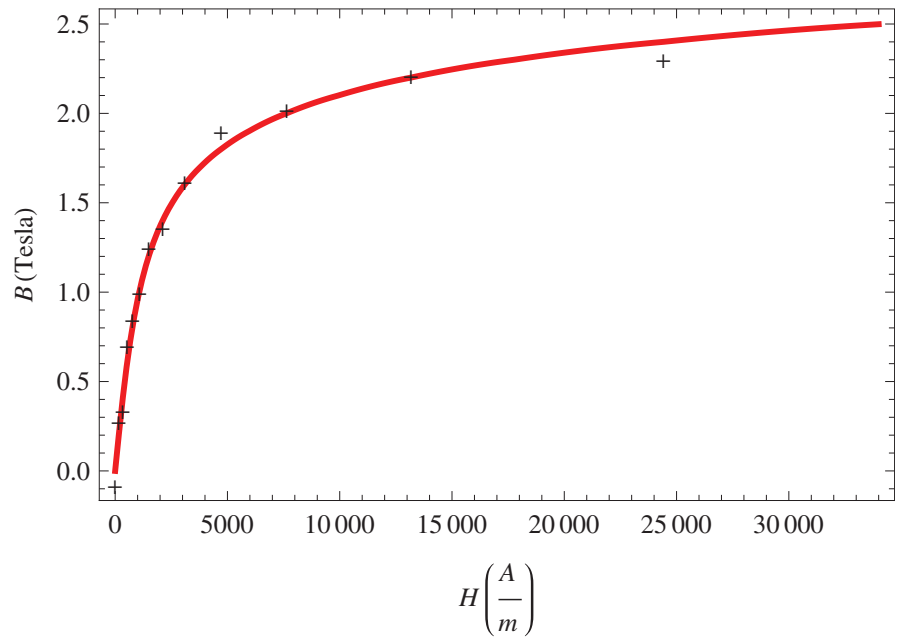

Fig. 3. Core saturation curve

considered as:

$$
\mu(B)=b \times e^{a \times B^{2}}
$$

where $a$ and $b$ are two constants which can be chosen for the best fitting of the saturation curve $(B-H)$ with this relation. By integrating Eq. (38) and combining with Eq. (40), the magnetic field intensity $H$ can be written as

$$
H(B)=\int \frac{1}{\mu(B)} d B=\frac{\sqrt{\pi} \operatorname{Erf}(\sqrt{a} \times B)}{2 b \sqrt{a}}
$$

where Erf is error function which is defined as: (Gautschi, 1964):

$$
\operatorname{Erf}(B)=\int e^{B^{2}} d B
$$

For instance, Fig. 3 shows a saturation curve $(B-H)$ for a silicon steel core that we can find two constants in Eq. (40) for the best fitting of the saturation curve. In this case, the two constants can be found as:

$$
\begin{aligned}
& a=-0.8 \\
& b=1000
\end{aligned}
$$

\section{Excitation vectors of reluctance network}

For determining relations between three phase currents with ampere-turn in the stator magnetic circuits, we give a contour between $(i-1)^{\text {th }}$ and $i^{\text {th }}$ stator teeth, yoke and slot in Fig. 1. Also, we suppose that combining of three phase conductors are placed in the stator slots. Therefore, by applying Ampere's law to this contour, $(i)^{\text {th }}$ ampere-turn of the stator magnetic circuits $\left(F_{i}^{S}\right)$ in Eq. (21) can be expressed as:

$$
F_{i}^{S}=w_{i}^{a} i_{a}+w_{i}^{b} i_{b}+w_{i}^{c} i_{c}
$$




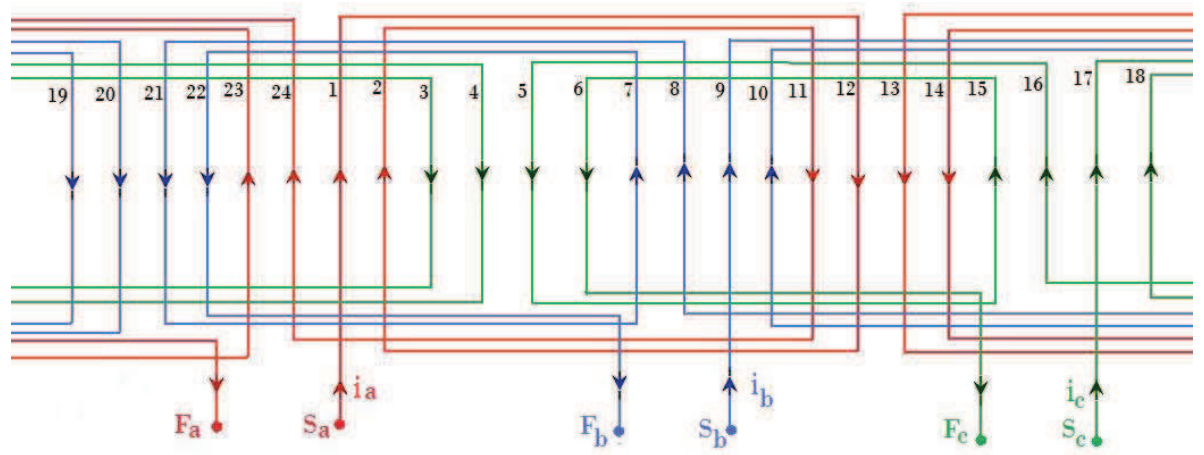

Fig. 4. Single layer distributed winding with 24 slot

where $w_{i}^{a}, w_{i}^{b}$ and $w_{i}^{c}$ are conductor numbers of phase $a, b$ and $c$ in the $i^{\text {th }}$ stator slot, respectively. Values and signs of these parameters will depend to connections and directions of windings in the $i^{\text {th }}$ slot. For instance, Fig. 4 shows a single layer three phase winding with two poles and 24 slots, which can generate a rotating magnetic field in the air gap. In this case, relation between ampere-turn of the stator magnetic circuits and stator currents can be determined as:

$$
\left[\begin{array}{c}
F_{1}^{s} \\
F_{2}^{s} \\
F_{3}^{S} \\
\vdots \\
F_{22}^{S} \\
F_{23}^{s} \\
F_{24}^{S}
\end{array}\right]=\left[\begin{array}{ccc}
-w^{a} & 0 & 0 \\
-w^{a} & 0 & 0 \\
0 & 0 & w^{c} \\
\vdots & \vdots & \vdots \\
0 & w^{b} & 0 \\
-w^{a} & 0 & 0 \\
-w^{a} & 0 & 0
\end{array}\right]\left[\begin{array}{l}
i_{a} \\
i_{b} \\
i_{c}
\end{array}\right]
$$

Thus, the stator ampere-turn vector $\left(\mathbf{F}_{S}\right)$ in Eq. (21) may be presented as

$$
\mathbf{F}_{s}=\mathbf{W}_{c} \mathbf{i}_{s}
$$

where $\mathbf{W}_{c} \in \mathbb{R}^{h \times 3}$, is a connection matrix that shows number of conductors in all of the stator slots. Also, $\mathbf{i}_{s}$ is a vector of three phase currents that we can arrange as:

$$
\mathbf{i}_{s}=\left[\begin{array}{lll}
i_{a} & i_{b} & i_{c}
\end{array}\right]^{T}
$$

In single layer winding, each slot can carry only one phase current, thus rows of the connection matrix in Eq. (46) have only one non-zero element. These non-zero elements can be determined by attention to stator winding topology.

In other respect, currents of rotor bars in squirrel cage induction machines are equal to current of conductors in the rotor slots. Therefore, similar to above mentioned method; the ampere-turn in rotor slots $\left(\mathbf{F}_{r}\right)$ in Eq. (22) can be determined by:

$$
\mathbf{F}_{r}=\mathbf{i}_{b}
$$


where $\mathbf{i}_{b}$, the rotor bars currents vector is defined as

$$
\mathbf{i}_{b}=\left[\begin{array}{llll}
i_{1}^{b} & i_{2}^{b} & \cdots & i_{l}^{b}
\end{array}\right]^{T}
$$

Substituting Eqs. (34), (35), (46) and (48) into (21) and (22) and combining with Eqs. (3) and (4), the magnetic algebraic equations of squirrel cage induction machines in matrix form can be augmented as

$$
\left[\begin{array}{cccc}
\mathbf{A}_{\phi s y}+\mathbf{A}_{\phi s t} \mathbf{A}_{s y t} & 0 & \mathbf{A}_{u s t} & 0 \\
0 & \mathbf{A}_{\phi r y}+\mathbf{A}_{\phi r t} \mathbf{A}_{r y t} & 0 & \mathbf{A}_{u r t} \\
-\mathbf{A}_{s y t} & 0 & \mathbf{A}_{s s} & \mathbf{A}_{s r} \\
0 & \mathbf{A}_{r y t} & \mathbf{A}_{r s} & \mathbf{A}_{r r}
\end{array}\right]\left[\begin{array}{c}
\Psi_{s y} \\
\Psi_{r y} \\
\mathbf{U}_{s t} \\
\mathbf{U}_{r t}
\end{array}\right]=\left[\begin{array}{c}
\mathbf{W}_{c} \mathbf{i}_{s} \\
\mathbf{i}_{b} \\
0 \\
0
\end{array}\right]
$$

Due to core saturation characteristic is a non-linear curve, the matrix Eq. (50) is non-linear and some coefficient matrices depends to the core fluxes density. Thus, ordinary methods cannot be employed for solving Eq. (50). Furthermore, rotor and stator currents are depended to stator three phase source voltages and rotor speed in differential equation forms. Therefore, for detailed analysis of squirrel cage induction machine, it is necessary to solve an electric, mechanic and magnetic algebraic differential equations, simultaneously

\section{Electrical voltage equations of squirrel cage induction machines}

Generally, a set of differential equations in an electrical machine is used to describe rates of the electrical and mechanical variables. These equations establish the relationship between fluxes, currents and the three phase source voltage variables. In the next section, rotor and stator voltage relations are be derived.

\subsection{Stator voltage equations}

For an induction machine, we can write electrical differential equations in stator windings as:

$$
\mathbf{V}_{s}=\mathbf{R}_{s} \mathbf{i}_{s}+\frac{d}{d t} \Lambda_{s}
$$

where $\mathbf{V}_{S}$ and $\mathbf{R}_{S}$ are voltage and stator resistances matrix, respectively which are defined by

$$
\begin{gathered}
\mathbf{V}_{s}=\left[\begin{array}{lll}
v_{a} & v_{b} & v_{c}
\end{array}\right]^{T} \\
\mathbf{R}_{s}=\operatorname{diag}\left[\begin{array}{lll}
r_{a} & r_{b} & r_{c}
\end{array}\right]
\end{gathered}
$$

Moreover, $\Lambda_{s}$ is linkage flux vector and equals to the product of turn number of stator windings and the phase fluxes. Thus, we can write:

$$
\begin{gathered}
\Lambda_{s}=\left[\begin{array}{lll}
\lambda_{a} & \lambda_{b} & \lambda_{c}
\end{array}\right]^{T} \\
\Lambda_{s}=w_{c} \Psi_{3 \varphi}
\end{gathered}
$$

By substituting Eqs. (34) and (37) into (55), we obtain:

$$
\Lambda_{s}=w_{c} \mathbf{M}_{c f} \mathbf{A}_{s y t} \Psi_{s y}
$$




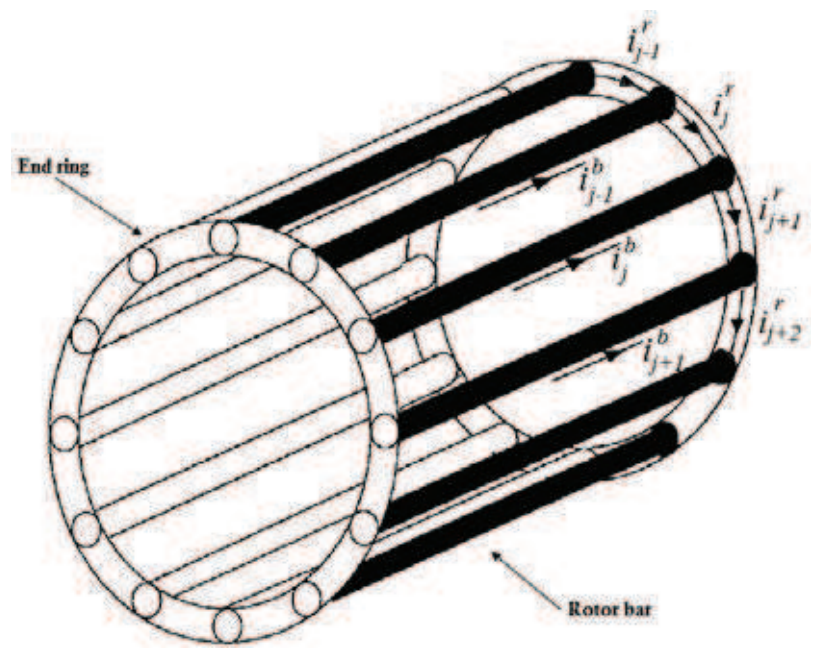

Fig. 5. Structure of squirrel cage rotor

\subsection{Rotor voltage equations}

Fig. 5 shows a structure of squirrel cage rotor in an induction machine. The rotor topology has $l+1$ mesh, thus we can write $l+1$ independent differential equations to describe electrical dynamic of rotor variables. Suppose, the rotor rings segments have a symmetrical structure, thus number of $l$ independent equations will be enough for modelling of the rotor dynamics. According to Fig. $1, j^{t h}$ tooth of rotor is surrounded by $j^{t h}$ and $(j+1)^{t h}$ rotor bars. Thus, based on currents directions of bars and ring segments which are shown in the Fig. 4; the voltage equation in this loop can be given by:

$$
\frac{d}{d t} \phi_{j}^{r t}=-2 i_{j+1}^{r} r_{j+1}^{r}-i_{j}^{b} r_{j}^{b}+i_{j+1}^{b} r_{j+1}^{b}
$$

This relation can be rearranged in the matrix form and the electrical differential equations for the rotor cage can be obtained as

$$
\frac{d}{d t} \Psi_{r t}=-2 \mathbf{J}_{r} \mathbf{R}_{r} \mathbf{i}_{r}-\mathbf{A}_{r y t} \mathbf{R}_{b} \mathbf{i}_{b}
$$

where the vector $\mathbf{i}_{r} \in \mathbb{R}^{l \times 1}, \mathbf{R}_{b} \in \mathbb{R}^{l \times l}$ and $\mathbf{R}_{r} \in \mathbb{R}^{l \times l}$ denote ring segment currents, rotor bar and ring segment resistance matrices, receptively. These vectors are given by:

$$
\begin{aligned}
\mathbf{i}_{r} & =\left[\begin{array}{llll}
i_{1}^{r} & i_{2}^{r} & \cdots & i_{l}^{r}
\end{array}\right]^{T} \\
\mathbf{R}_{r} & =\operatorname{diag}\left[\begin{array}{llll}
r_{1}^{r} & r_{2}^{r} & \cdots & r_{l}^{r}
\end{array}\right] \\
\mathbf{R}_{b} & =\operatorname{diag}\left[\begin{array}{llll}
r_{1}^{b} & r_{2}^{b} & \cdots & r_{l}^{b}
\end{array}\right]
\end{aligned}
$$


Also, constant matrix $\mathbf{J}_{r} \in \mathbb{R}^{l \times l}$ is defined as

$$
\mathbf{J}_{r}=\left[\begin{array}{cccccc}
0 & 1 & 0 & \cdots & 0 & 0 \\
0 & 0 & 1 & \cdots & 0 & 0 \\
0 & 0 & 0 & \cdots & 0 & 0 \\
\vdots & \vdots & \vdots & \ddots & \vdots & \vdots \\
0 & 0 & 0 & \cdots & 0 & 1 \\
1 & 0 & 0 & \cdots & 0 & 0
\end{array}\right]
$$

Moreover, there are two current vectors in left hand side of Eq. (58) which have to find a relation between them. For this propose, Kirchhoff's Current Law (KCL) can be used to determined a relation between rotor bars and ring segments currents. By applying KCL to $j^{\text {th }}$ node (bar) in the rotor cage (Fig. 4), we can write:

$$
i_{j}^{b}=i_{j+1}^{r}-i_{j}^{r}
$$

Therefore, for $l$ nodes in the rotor cage; Eq. (63) can be expressed in matrix form as:

$$
\mathbf{i}_{b}=\mathbf{A}_{r y t} \mathbf{i}_{r}
$$

By substituting Eqs. (64) into (58), we can get:

$$
\frac{d}{d t} \Psi_{r t}=\left(-2 \mathbf{J}_{r} \mathbf{R}_{r}+\mathbf{A}_{r y t} \mathbf{R}_{b} \mathbf{A}_{r y t}\right) \mathbf{i}_{r}
$$

Up to this stage, two separate sets of non-linear equations are derived to established of algebraical (magnetic) and dynamicalal (electric) models of a squirrel cage induction machine. By combining of Eqs. (50), (51) and (65), the total algebria-differential equations of the system can be augmented as:

$$
\left[\begin{array}{cccccc}
w_{c} \mathbf{M}_{c f} \mathbf{A}_{s y t} p & 0 & 0 & 0 & \mathbf{R}_{s} & 0 \\
0 & \mathbf{A}_{r y t} p & 0 & 0 & 0 & 2 \mathbf{J}_{r} \mathbf{R}_{r}-\mathbf{A}_{r y t} \mathbf{R}_{b} \mathbf{A}_{r y t} \\
\mathbf{A}_{\phi s y}+\mathbf{A}_{\phi s t} \mathbf{A}_{s y t} & 0 & \mathbf{A}_{u s t} & 0 & -\mathbf{W}_{c} & 0 \\
0 & \mathbf{A}_{\phi r y}+\mathbf{A}_{\phi r t} \mathbf{A}_{r y t} & 0 & \mathbf{A}_{u r t} & 0 & \mathbf{A}_{r y t} \\
-\mathbf{A}_{s y t} & 0 & \mathbf{A}_{s s} & \mathbf{A}_{s r} & 0 & 0 \\
0 & -\mathbf{A}_{r y t} & \mathbf{A}_{r s} & \mathbf{A}_{r r} & 0 & 0
\end{array}\right]\left[\begin{array}{c}
\Psi_{s y} \\
\Psi_{r y} \\
\mathbf{U}_{s t} \\
\mathbf{U}_{r t} \\
\mathbf{i}_{s} \\
\mathbf{i}_{r}
\end{array}\right]=\left[\begin{array}{c}
\mathbf{V}_{s} \\
0 \\
0 \\
0 \\
0 \\
0
\end{array}\right]
$$

where $p$ denotes time derivative operator $\left(\frac{d}{d t}\right)$.

\subsection{Mechanical differential equations}

Some of the matrix coefficients in Eq.(66) are depended to mechanical instantaneous angle $\gamma$. In variable speed conditions, the mechanical variables of the system can be determined by solving differential equations of the rotor angel and speed. Generally, mechanical torque balance equation can be expressed as:

$$
J \frac{d \omega}{d t}=T_{e m}-T_{l}
$$




\begin{tabular}{lcc}
\hline \hline Quantity & Symbol & Value \\
\hline Power & $P$ & $1.1 \mathrm{kw}$ \\
Voltage & $V$ & $220 \mathrm{~V}$ \\
Frequency & $f$ & $50 \mathrm{~Hz}$ \\
Number of pole & $p$ & 2 \\
Stator resistance & $r_{s}$ & $5 \Omega$ \\
Rotor bar resistance & $r_{b}$ & $20 \mu \Omega$ \\
Rotor ring sector resistance & $r_{e}$ & $1.1 \mu \Omega$ \\
Inertia moment & $j$ & $0.02 \mathrm{kgm}^{2}$ \\
Number of turns per slot & & 68 \\
Number of rotor slots & & 18 \\
\hline \hline
\end{tabular}

Table 1. Parameters of squirrel cage induction machine

in which

$$
\frac{d \gamma}{d t}=\omega
$$

also, $\omega, J, T_{l}$ and $T_{e m}$ are the rotor angular speed, total inertia on the shaft, load torque and electromagnetic torque, respectively. The electromagnetic torque is depended to mmf along air gap and derivative of air gap permeances with respect to rotor angel $(\gamma)$ (Ostovic, 1989). For an induction machines, we can express as:

$$
T_{e m}=\sum_{i=1}^{h} \sum_{j=1}^{l}\left(u_{i}^{s t}-u_{j}^{r t}\right)^{2} \frac{d G_{i, j}(\gamma)}{d \gamma}
$$

By substuting Eqs.(7), (10) and (11) into (69), air gap electromagnetic torque can be obtained as:

$$
T_{e m}=\left(\mathbf{U}_{s t}^{T}-\mathbf{U}_{r t}^{T}\right) \frac{d}{d \gamma} \mathbf{A}_{\mathbf{s r}}\left(\mathbf{U}_{s t}-\mathbf{U}_{r t}\right)
$$

Therefore, the mechanical non-linear differential equations (67) to (70), with the magnetic non-linear differential-algebraic equations (66), describe the generalized non-linear dynamic model of squirrel cage induction machine. Because of non-linearity of the model, the advantage numerical solution methods must be used. In the next section, some simulation results are presented for demonstration of capability validation of the new model. After that, asymmetrical situations of squirrel cage induction machine such as broken rotor bar fault with saturation effects are analysed and evaluated.

\section{Simulations and experiment of results}

Table 1 shows the electrical parameters of the squirrel cage induction machine which is used to obtain numerical simulation and experimental results. Air gap, rotor and stator slots and other main dimensions of the induction machines are presented in Fig. (5) and windings connection diagram are assumed similar to Fig. (4). In the next section, some different dynamical conditions are implemented to obtain numerical results of the non-linear model of induction machines. 

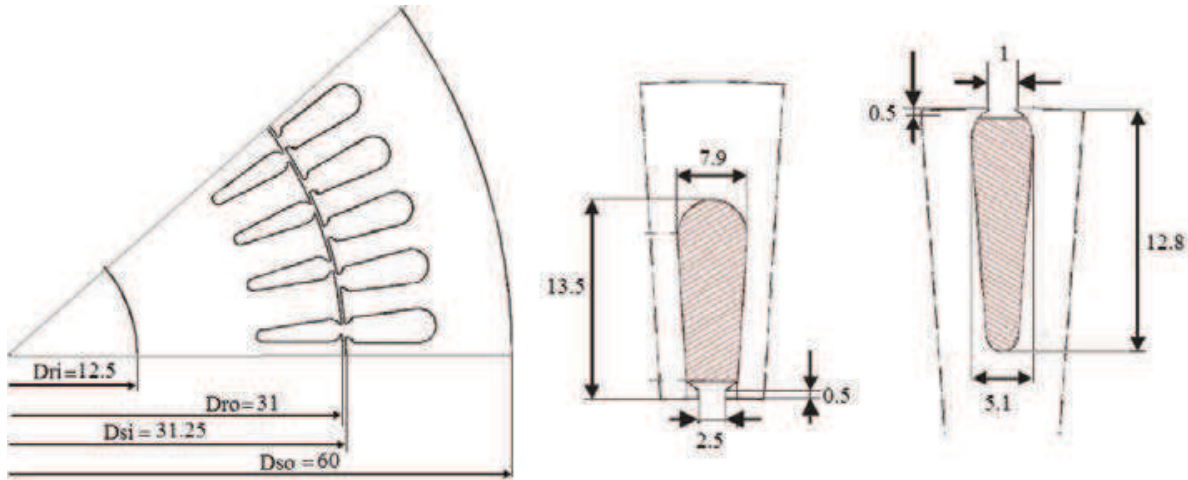

Fig. 6. Basic construction and main diameters and stator and rotor slot shapes

\subsection{Simulation in healthy condition}

For simulation study, the healthy conditions of a squirrel cage induction machine with saturable iron core are given. At first, free starting-up is considered and at $t=0.3 \mathrm{sec}$, a mechanical load $\left(T_{l}=10 \mathrm{Nm}\right)$ is applied to the rotor shaft. The results of the simulations are shown in Figs. 7 and 8. Speed-torque transient acceleration of the system is presented in Fig. 7 -a, that rotor speed reaches to steady state value at about $t=0.2 \mathrm{sec}$. Also, transient electromagnetic torque are shown in Fig. 7-a where low order harmonics are appeared in the electromagnetic torque on the transient duration. This is a common behaviour in the induction machines, which can be obtained from classical method such as two axes theory. But the high order harmonics in transient and steady state are also appeared in the results. At $t=0.3 \mathrm{sec}$ load torque changes form zero to $T_{l}=10 \mathrm{~N} . \mathrm{m}$, electromagnetic torque increase by decreasing of the rotor speed. Fig. 7-b shows dynamic of three phase stator currents which decrease by increasing the rotor speed. Other dynamic performance for flux and rotor bar currents are shown in Fig. 8. The results show that, high order harmonics are observed in the rotor and stator teeth fluxes and currents. The rotor teeth and slots are moved opposite the stator teeth and slots, thus radial fluxes will have variable permeances in the air gap. This is caused a slot harmonics appears in the the all variables of the system. Fig 8-a illustrates that, slot harmonics deform the stator teeth flux in the transient and steady state conditions. Because of the machine is symmetric, all variables of machine such as the stator currents and stator teeth flux are balanced.

\subsection{Simulation in faulty condition}

In this simulation, analysis of the induction machine with a broken bar is done to determined the steady state performances of the machine. Fig. 9-a shows the steady state current of the stator winding with linear and non-linear core characteristics. The rotor speed and torque are $307.7 \mathrm{rad} / \mathrm{sec}$ and $10 \mathrm{~N} . \mathrm{m}$, respectively. Similar to the last conditions, slot harmonics are appeared on the stator currents in the both causes (linear and non-linear magnetic core). However, stator current has low order harmonics with the non-linear iron core. Stator teeth fluxes in two cases are approximately equal. Also, Fig. 9-c presents that the bar currents near to the broken bar are strongly changed. But attention to Fig 9-d, this situation is not appeared in induction machine with non-linear magnetic core. Therefore, disturbances of rotor broken bar in the saturated machines cannot effectively transfer to the stator currents. 


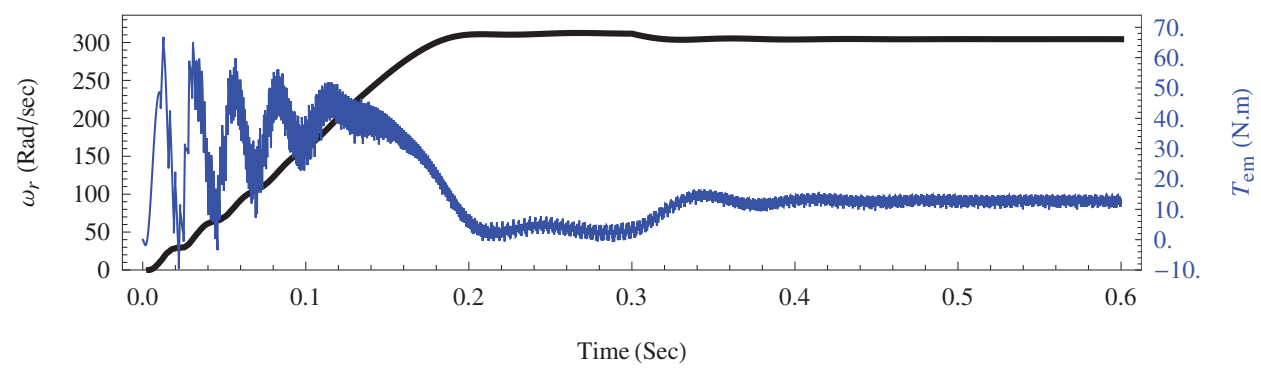

(a) Torque-speed dynamic

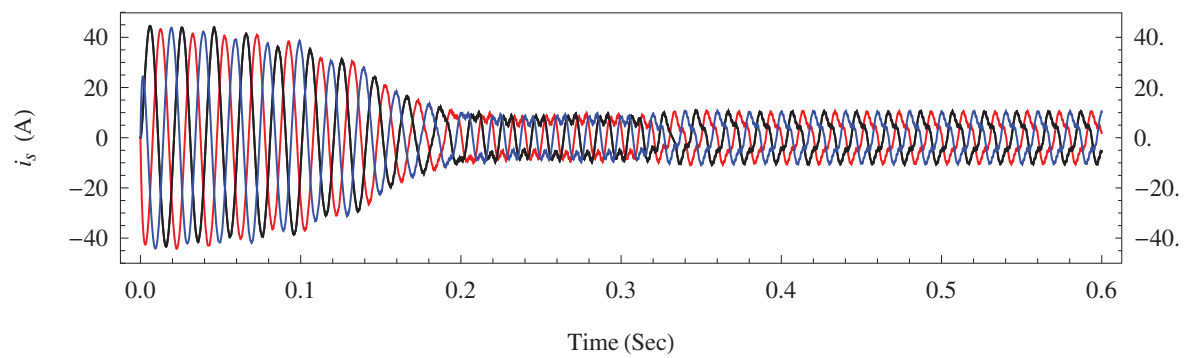

(b) Stator currents

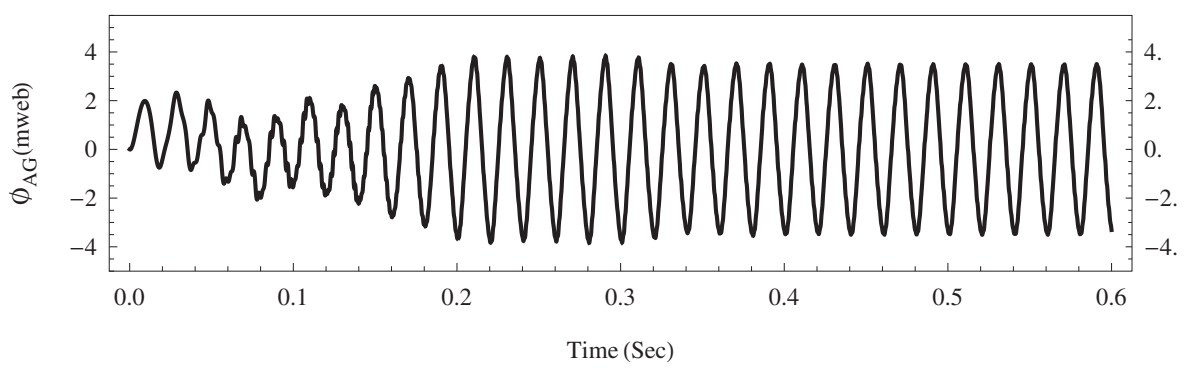

(c) Air gap flux

Fig. 7. Starting-up transient of induction machine

\section{Conclusion}

In this chapter, a generalized non-linear dynamical model of the squirrel cage induction machines was presented. In this modelling, magnetic saturation effects in iron core, space harmonic distributed of fluxes in the rotor and stator teeth, the stator windings and rotor bar distribution were considered. Some simulations results showed that, presented model has high accuracy and efficiency for asymmetrical analysis such as broken bar conditions. The effects of broken bar will not clearly appear when the machine core is saturated. 


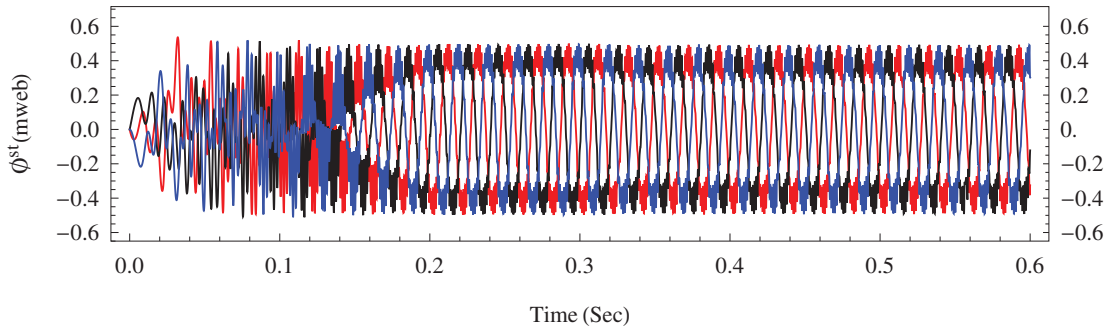

(a) Stator teeth Fluxes

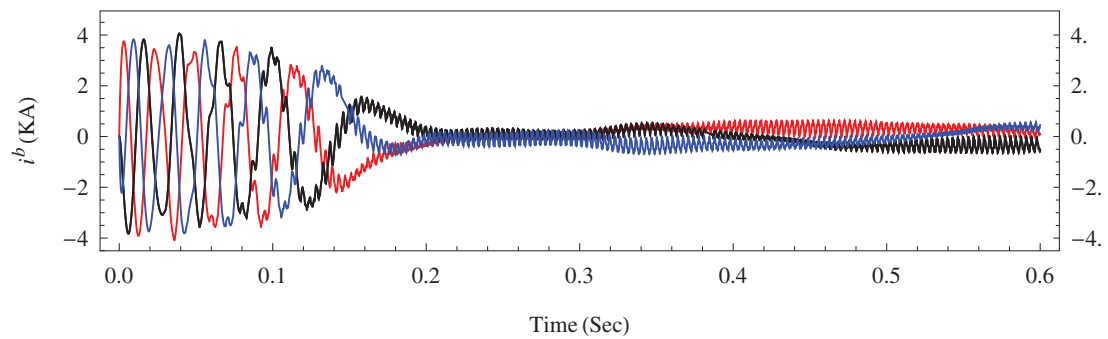

(b) Rotor bar currents

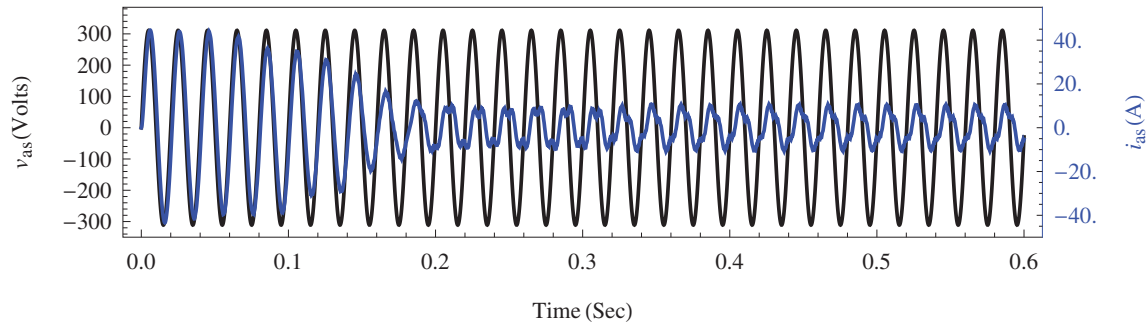

(c) Stator voltage and current

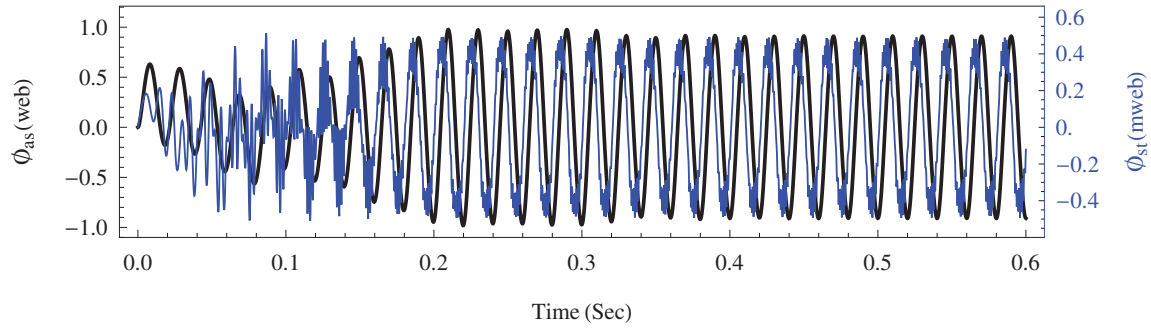

(d) Tooth and phase fluxes

Fig. 8. Starting-up transient of induction machine 


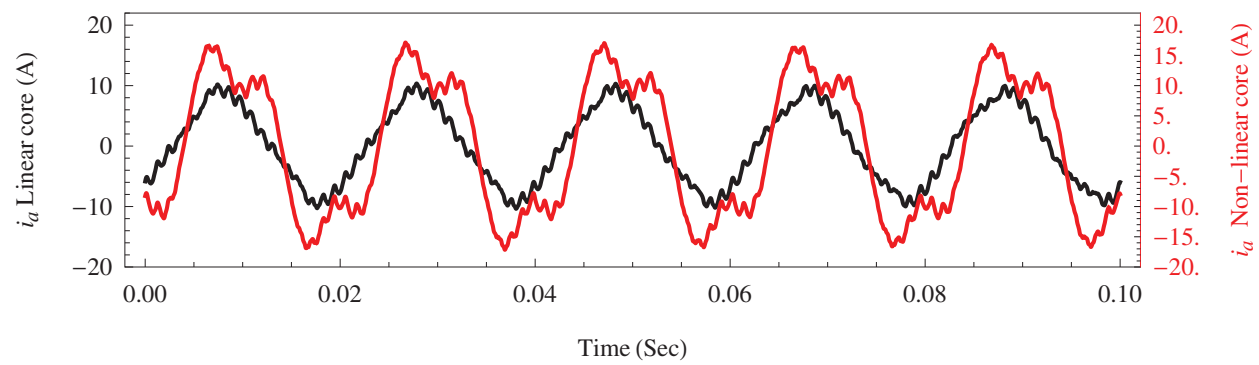

(a) Stator current

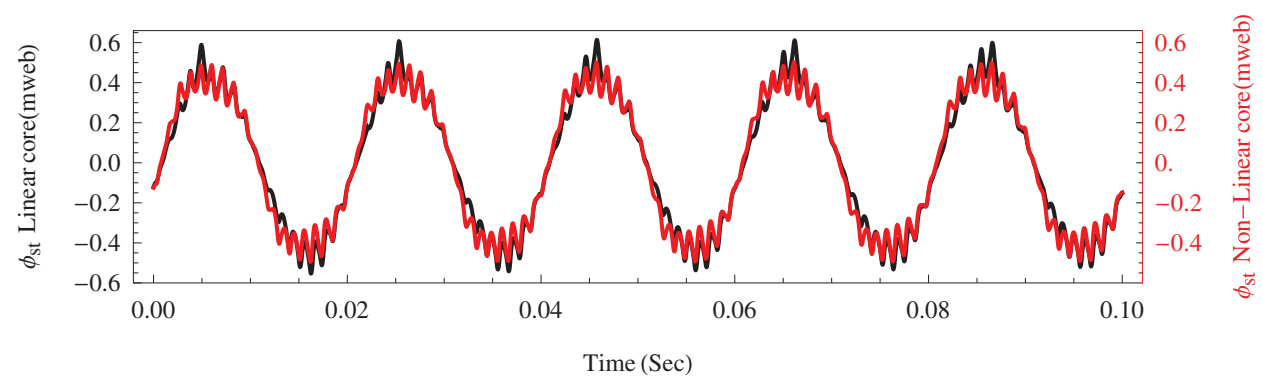

(b) Stator flux

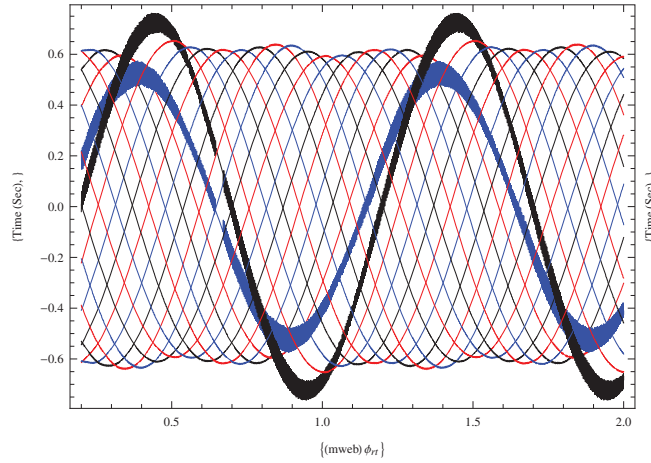

(c) Rotor fluxes with linear core

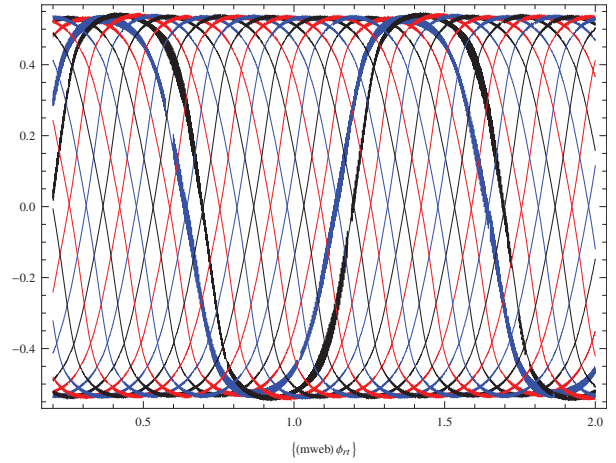

(d) Rotor fluxes with non-linear core

Fig. 9. Steady state fluxes and currents of faulty induction machine with a broken bar for linear and non-linear core

\section{References}

Alemi, P. \& Nazarzadeh, J. (2006). The Induction machines modeling based on bars current for rotor fault analysis, $21^{\text {th }}$ International Power System Conference, PSC 2006, 477-483, Niroo Research Institute, 13-15 Nov. 2006, Tehran, Iran 
Al-Shahrani, A. S. (2005). Influence of adjustable speed drive on induction motor fault detection using stator current monitoring. Ph.D. thesis, Oregon State University

Bellini, A.; Filippetti, F.; Franceschini, G.; Tassoni, C. \& Kliman G. B. (2001). Quantitative evaluation of induction motor broken bars by means of electrical signature analysis. IEEE Transactions on Industry Applications, Vol. 37, No. 5, (Sep./Oct. 2001), 1248-1255

Benbouzid, M. E. H. (2000). A review of induction motors signature analysis as a medium for faults detection.IEEE Transactions on Industry Electronics, Vol. 47, No. 5, (Oct. 2000), 984-993

Chen, S. D.; Lin, R. L \& Cheng, C. K.(2005). Magnetizing inrush model of transformers based on structure parameters.IEEE Transactions on Industry Electronics, Vol. 20, No. 3, (July 2005), 1947-1954

Faiz, J.; Sharifian, M. B. B.; Feyzi, M. R.; \& Shaarbafi, K. (2002). A complete lumped equivalent circuit of three-phase squirrel-cage induction motors using two-dimensional finite-elements technique. IEEE Transactions on Energy Conversion, Vol. 17, No. 3, (Spet. 2002), 363-367

Gautschi W. (1964). Error function and Fresnel integrals, Handbook of Mathematical Functions, NBS Appl. Math. Series, Vol. 55, U.S. Government Printing Office, Washington, D.C.

Jeong, J. H.; Lee E. W. \& Cho, H. K. (2003). Analysis of transient state of the squirrel cage induction motor by using magnetic equivalent circuit method, Sixth International Conference on Electrical Machines and Systems, Vol. 2, 720-723, 2003

Jung, J. H.; Lee, J. J. \& Kwon, B. H. (2006). Online diagnosis of induction motors using MCSA. IEEE Transactions on Industry Electronics, Vol. 53, No. 6, (Dec 2006), 1842-1852

Krause, P. C.; Wasynczuk, O. \& Sudhoff, S. D. (2002). Analysis of Electric Machinery and Drive Systems (2nd Edition), Wiley-IEEE Press, ISBN 047114326X, New York.

Luos, X.; Liao, Y.; Toliyaty, H.; El-Antably, A. \& Lipos, T. A. (1995). Multiple coupled circuit modeling of induction machines. IEEE Transactions on Industry Applications, Vol. 31, No.2, (Mar. / Apr. 1995), 311-318

Mirafzal, B.\& Demerdash, N. A. O. (2004). Induction machine broken-bar fault diagnosis using the rotor magnetic field space-vector orientation. IEEE Transactions on Industry Applications, Vol. 40, No. 2, (Mar. / Apr. 2004), 534-542

Mirafzal, B.\& Demerdash, N. A. O. (2008). Induction machine broken bar and stator short-circuit fault diagnostics based on three-phase stator current envelopes. IEEE Transactions on Industry Applications, Vol. 55, No. 3, (March 2008), 1310-1318

Muñoz, A. R. \& Lipo, T. A. (1999). Complex vector model of the squirrel-cage induction machine including instantaneous rotor bar currents. IEEE Transactions on Industry Applications, Vol. 35, No. 6, (Nov./Dec. 1999), 1332-1340

Ostovic, V. (1989). A novel method for evaluation of transient states in saturated electric machine. IEEE Transactions on Industry Applications, Vol. 25, No. 1, (Feb. 1989), 96-1000

Ostovic, V. (1989). Dynamics of Saturated Machines, Springer-Verlag, ISBN 0387970797, New York

Siddique, A.; Yadava, G. S. \& Singh, B. (2005). A review of stator fault monitoring techniques of induction motors. IEEE Transactions on Energy Conversion, Vol. 20, No. 1, (March 2005), 106-114

Sprooten, J. (2007). Finite element and electrical circuit modeling of faulty induction machines study of internal effects and fault detection techniques. Ph.D. thesis, Department of Bio, Electro and Mechanical Systems (BEAMS), University Libre de Bruxelles 
$\mathrm{Su}, \mathrm{H}$. \& Chong, K. T. (2007). Induction machine condition monitoring using neural network modelling. IEEE Transactions on Industry Applications, Vol. 54, No. 1, (Feb. 2007), 241-249 


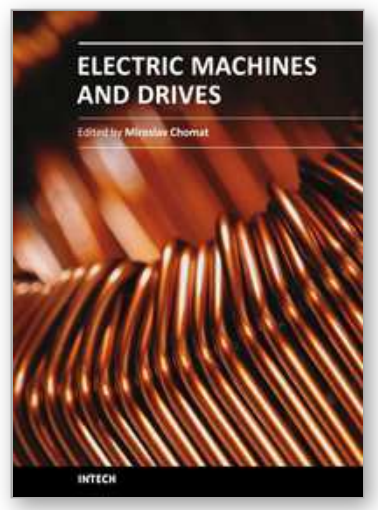

\author{
Electric Machines and Drives \\ Edited by Dr. Miroslav Chomat
}

ISBN 978-953-307-548-8

Hard cover, 262 pages

Publisher InTech

Published online 28, February, 2011

Published in print edition February, 2011

The subject of this book is an important and diverse field of electric machines and drives. The twelve chapters of the book written by renowned authors, both academics and practitioners, cover a large part of the field of electric machines and drives. Various types of electric machines, including three-phase and single-phase induction machines or doubly fed machines, are addressed. Most of the chapters focus on modern control methods of induction-machine drives, such as vector and direct torque control. Among others, the book addresses sensorless control techniques, modulation strategies, parameter identification, artificial intelligence, operation under harsh or failure conditions, and modelling of electric or magnetic quantities in electric machines. Several chapters give an insight into the problem of minimizing losses in electric machines and increasing the overall energy efficiency of electric drives.

\title{
How to reference
}

In order to correctly reference this scholarly work, feel free to copy and paste the following:

Jalal Nazarzadeh and Vahid Naeini (2011). Magnetic Reluctance Method for Dynamical Modeling of Squirrel Cage Induction Machines, Electric Machines and Drives, Dr. Miroslav Chomat (Ed.), ISBN: 978-953-307-5488, InTech, Available from: http://www.intechopen.com/books/electric-machines-and-drives/magneticreluctance-method-for-dynamical-modeling-of-squirrel-cage-induction-machines

\section{INTECH}

open science | open minds

\author{
InTech Europe \\ University Campus STeP Ri \\ Slavka Krautzeka 83/A \\ 51000 Rijeka, Croatia \\ Phone: +385 (51) 770447 \\ Fax: +385 (51) 686166 \\ www.intechopen.com
}

\author{
InTech China \\ Unit 405, Office Block, Hotel Equatorial Shanghai \\ No.65, Yan An Road (West), Shanghai, 200040, China \\ 中国上海市延安西路65号上海国际贵都大饭店办公楼 405 单元 \\ Phone: +86-21-62489820 \\ Fax: +86-21-62489821
}


(C) 2011 The Author(s). Licensee IntechOpen. This chapter is distributed under the terms of the Creative Commons Attribution-NonCommercialShareAlike-3.0 License, which permits use, distribution and reproduction for non-commercial purposes, provided the original is properly cited and derivative works building on this content are distributed under the same license. 